\title{
CLUBES DE FUTEBOL E 0 DESENVOLVIMENTO DO ESPORTE ELETRÔNICO NO BRASIL
}

\author{
Miguel Soveral Sampaio
}

Trabalho de Conclusão de Curso

Centro de CIÊnCIAS SOCIAIS - CCS

DePARTAMENTO de AdMINISTRAÇÃo

Graduação em Administração de Empresas 
Miguel Soveral Sampaio

\section{CLUBES DE FUTEBOL E O DESENVOLVIMENTO DO ESPORTE ELETRÔNICO NO BRASIL}

Trabalho de conclusão de curso

Trabalho de Conclusão de Curso, apresentado ao programa de graduação em Administração da PUC-Rio como requisito parcial para a obtenção do título de graduação em Administração.

Orientador: Marco Aurélio de Sá Ribeiro

Rio de Janeiro, novembro de 2019 


\section{Agradecimentos}

Gostaria de agradecer primeiramente à minha família, especialmente meus pais, Paulo e Barbara e meu irmão, Tiago, por todo apoio durante o período da faculdade, especialmente na decisão de trocar de curso, dando todo suporte e incentivo.

Também gostaria de agradecer à Elisa Ferreira, por todo apoio nos últimos dois anos, acompanhando de perto e apoiando também em todos os momentos.

Ao pessoal da Go4it, por me mostrarem e me permitirem descobrir o universo dos esportes eletrônicos, especialmente ao Thiago Milhazes, Felipe Borges e Gabriel Duarte pela contribuição dada a este trabalho.

Por fim, gostaria de agradecer a todos os professores da PUC-Rio, especialmente o meu orientador Marco Aurélio de Sá Ribeiro, pelo apoio dado durante a elaboração do presente trabalho. 


\section{Resumo}

Sampaio, Miguel Soveral. Clubes de futebol e o desenvolvimento do esporte eletrônico no Brasil. Rio de Janeiro, 2019. Número de páginas p.33. Trabalho de Conclusão de Curso - Departamento de Administração. Pontifícia Universidade Católica do Rio de Janeiro.

O mercado de esportes eletrônicos vem nos últimos anos crescendo de forma exponencial. Com o surgimento de um novo mercado, surgem diversas novas oportunidades de negócios, novas marcas, novas públicos e principalmente novas fontes de receita. O mercado brasileiro é um dos mais promissores do mundo e pode se tornar um dos principais mercados no mundo. Como podemos transformar esse potencial em realidade? Como os tradicionais clubes de futebol do país podem se aproveitar para expandir sua marca e criar novos negócios?

Palavras chaves

eSports, esporte eletrônico, estratégia, clubes de futebol, desenvolvimento 


\section{Abstract}

The eSports market is growing exponentially worldwide. With a new market, new business opportunities, new brands, new publics and especially new revenue sources are born. The brazilian market is one of the most promising one and can be one of biggest in the world. How to thrive this potential into reality? How traditional soccer teams can play a big part in this process, to expand their brands and build new business?

Key words

eSports, strategy, soccer teams, development 


\section{Sumário}

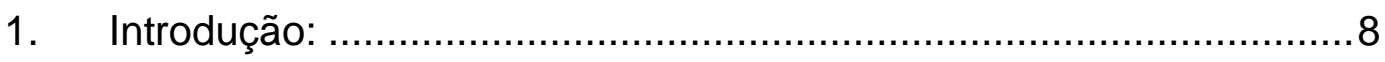

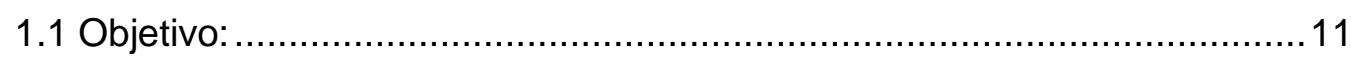

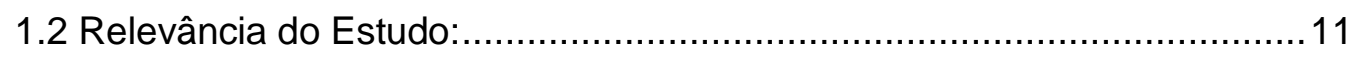

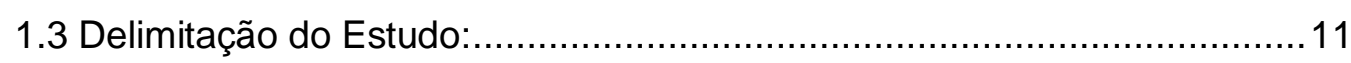

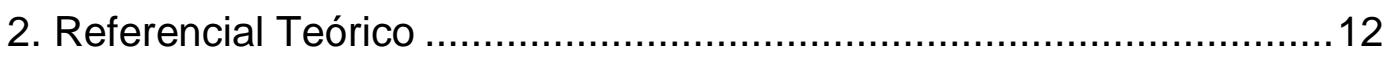

2.1 Esporte Eletrônico: .........................................................................

2.2 Modelo VBR - Visão Baseada em Recursos..........................................12

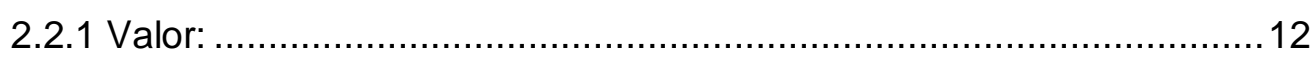

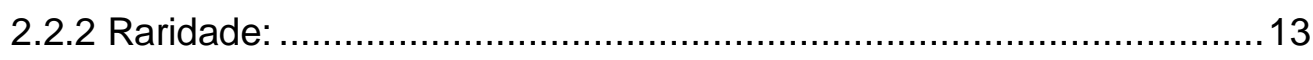

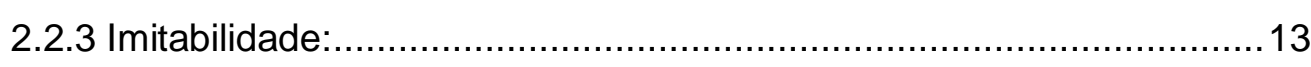

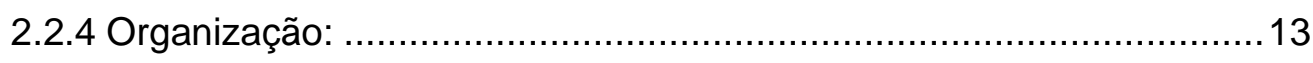

2.3 Modelo das 5 forças de Porter............................................................. 13

2.3.1 Ameaça de novos entrantes:.......................................................... 14

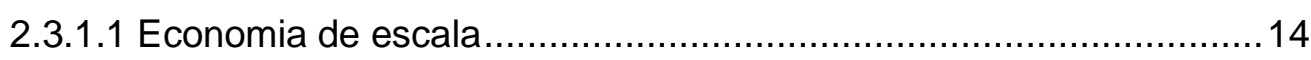

2.3.1.2 Diferenciação de Produtos ........................................................... 15

2.3.1.3 Necessidade de Capital ............................................................15

2.3.1.4 Acesso a canais de distribuição ...................................................15

2.3.2 Poder de barganha dos fornecedores ............................................15

2.3.3 Ameaça de produtos substitutos ....................................................16

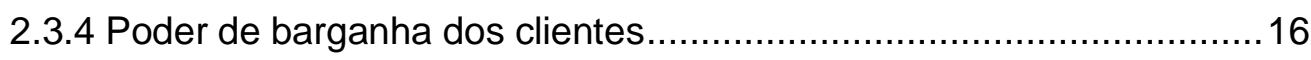

2.3.5 Rivalidade entre concorrentes...................................................... 16

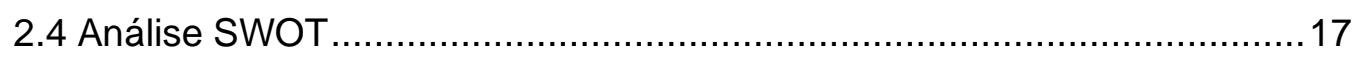

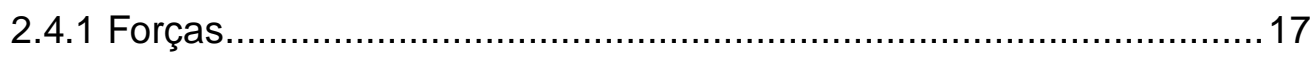

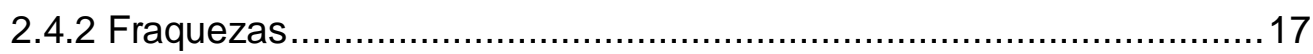

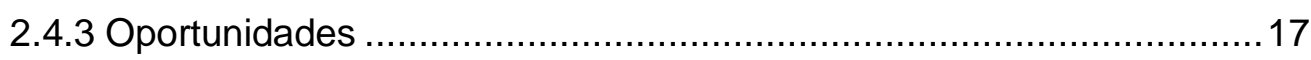

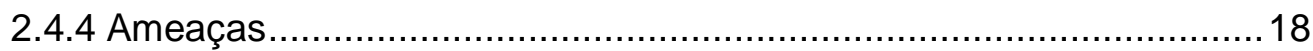

3. Metodologia de Pesquisa ............................................................. 19

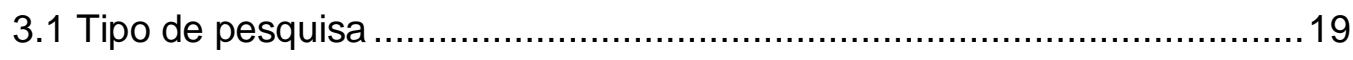

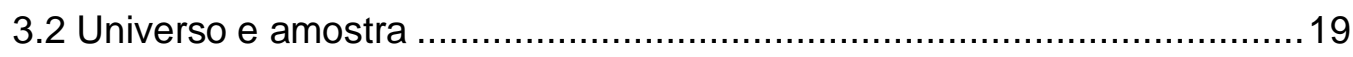

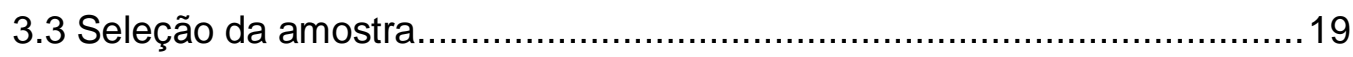

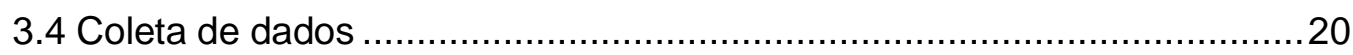

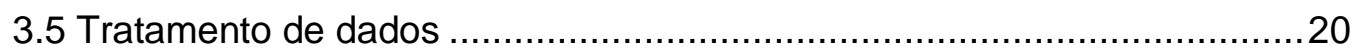

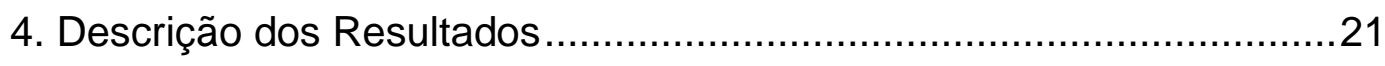

4.1 O preconceito com o esporte eletrônico ………………………….........21 


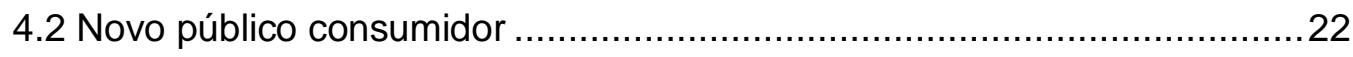

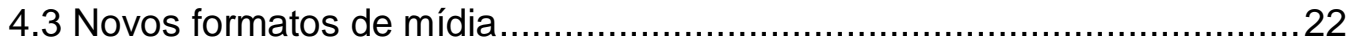

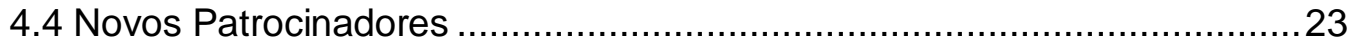

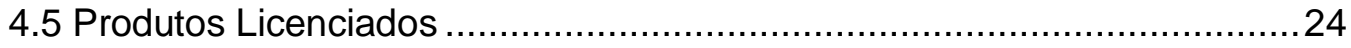

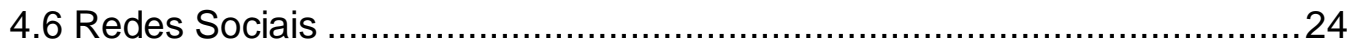

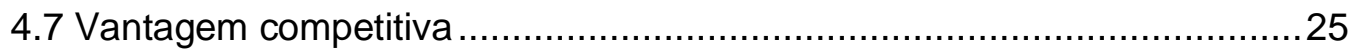

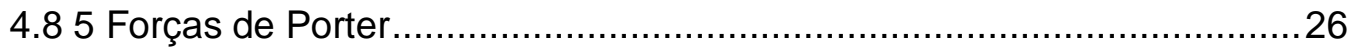

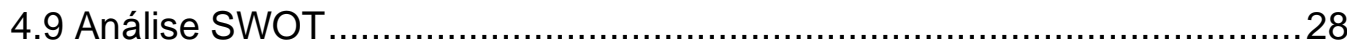

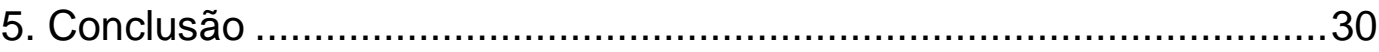

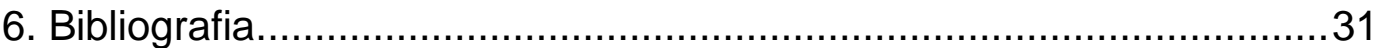

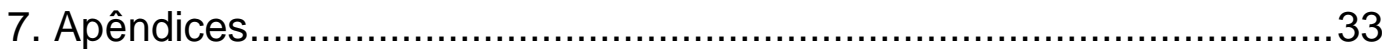

\section{Lista de Figuras}

Figura 1: O Modelo das Cinco Forças de Porter (PORTER, M., 1979)...............14

Figura 2 - Matriz SWOT - desenvolvido pelo autor............................................28 


\section{Introdução:}

O primeiro jogo eletrônico surgiu no início da década de 1970, com o Pong, criado por Nolan Bushnell, estudante de engenharia da Universidade de Utah (EUA). A partir dele, não demorou muito para surgirem as primeiras competições de esportes eletrônicos, popularmente conhecidos como eSports. A primeira competição que se tem registro ocorreu na Universidade de Stanford com o jogo Spacewar, cujo nome oficial foi "Olimpíadas Intergalácticas de Spacewar" e a premiação um ano de assinatura da revista Rolling Stone.

O primeiro grande salto da história dos eSports ocorreu na década de 1990, com o surgimento e desenvolvimento da internet, permitindo que milhões de pessoas joguem ao mesmo tempo em diferentes partes do mundo. Nessa época surgiram dois dos jogos mais populares da história, o Warcraft, desenvolvido pela Blizzard Entertainment, e lançado em novembro de 1994 e o Counter Strike, desenvolvido pela Valve e lançado em 1999. Nesse período começaram a aparecer os primeiros grandes campeonatos de eSports, como o Cyberathlete Professional League, a organização pioneira na promoção e fomento do esporte eletrônico.

Os anos 2000 viram o segundo grande salto da história da modalidade, com diversos novos jogos sendo lançados, com a profissionalização dos atletas, o interesse de grandes empresas e a explosão das premiações em dinheiro, que alcançou U\$30.000.000,00 no The International 2019, de Dota 2. Para efeito de comparação, a Copa do Mundo de Futebol Masculino, que ocorreu pela última vez em 2018, na Rússia, pagou cerca de U\$38.000.000,00 ao seu campeão, o que mostra a grande evolução do esporte eletrônico em pouco tempo.

No Brasil, o cenário dos eSports teve seu início no final dos anos 1990 e início dos anos 2000. Um dos primeiros torneios a se ter registro foi a Primeira Olimpíada Brasileira de Videogames, organizada pela Supergame, revista especializada em Videogames, em 1992 e que teve como prêmio, uma viagem para a Disney. Enquanto no exterior os principais jogos já migravam para o modelo online, ou seja, dependiam de conexão à internet, no Brasil enfrentava essa barreira, que retardou o crescimento e a popularização do esporte eletrônico no país. Nesse contexto, surgiram em São Paulo, primeiramente, e depois se espalhando por todo Brasil, as Lan-Houses, estabelecimentos comerciais que dispunham de conexão de Internet, onde se jogavam 
casualmente jogos online. O que no início era apenas um local para jogadores amadores e partidas casuais se tornou um negócio lucrativo e logo surgiram os primeiros torneios de esportes eletrônicos. Por esse motivo, as Lan-Houses são consideradas nos dias de hoje o berço dos eSports no Brasil, de onde surgiram grandes jogadores, hoje profissionais, de sucesso internacional, como por exemplo Gabriel "Fallen" Toledo, atleta de Counter Strike: Global Offensive (popularmente conhecido como CS:GO) e Marcelo "coldzera" David, também atleta de CS:GO. Um dos mais emblemáticos torneios organizados nas Lan Houses foi o MAX5 Invitational, organizado pela MAX5, em 2016, com premiação de $\mathrm{R} \$ 38.000,00$.

Segundo a Newzoo, consultoria especializada em eSports e Games, o Brasil possui 7,6 milhões de entusiastas de eSports (2018 GLOBAL ESPORTS

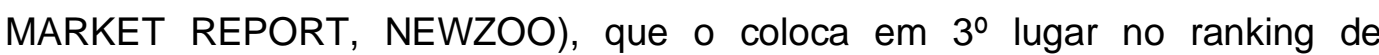
entusiastas.

Com o desenvolvimento do mercado, muitos clubes tradicionais pelo futebol, especialmente fora do Brasil, formaram times de eSports, visando participar dos grandes torneios, alcançar novos fãs e gerar novas fontes de receitas. Entre os principais times oriundos do futebol estão o Schalke 04, da Alemanha, o Fenerbahce, da Turquia, e o Paris Saint Germain, da França. Alguns clubes brasileiros abraçaram a ideia e deram início a projetos de equipes de eSports. Sem dúvida, a equipe que teve o maior sucesso foi o Flamengo, com o Flamengo eSports, com seu time de League of Legends. Anunciado em outubro de 2017, o Flamengo eSports iniciou seu projeto cercado de grandes expectativas. Logo em seu primeiro split no Circuito Desafiante, espécie de segunda divisão do Campeonato Brasileiro de League of Legends (CBLOL), o Flamengo eSports, terminou na segunda colocação, e depois obteve a classificação para o CBLOL ao derrotar a tradicional Team One na série de acesso, uma espécie de repescagem. Em pouco tempo de vida o Fla eSports já possuía milhares de fãs e seguidores nas redes sociais, impulsionado pela maior torcida do país, e contava em seu elenco a maior estrela do cenário nacional de League of Legends, Felipe "brTT" Gonçalves, na época tetra campeão do CBLOL. Somando uma grande torcida, com um time em rápida ascensão e uma grande estrela no time, o Flamengo eSports causou um grande impacto no mercado de esporte eletrônico brasileiro. Apesar de outros times tradicionais do futebol terem se aventurado nos eSports, como o Santos-SP e o Remo-PA, o 
Flamengo foi o pioneiro em ter uma organização dedicada à modalidade. Em recente entrevista ao blog Techtudo, Carlos Antunes, diretor de eSports da Riot Games no Brasil, a entrada do Flamengo no cenário de eSports fez com que fosse dada muito mais atenção à indústria, o que beneficiou todos os envolvidos no meio, como times, jogadores, patrocinadores e fãs. Carlos complementa que a criação do time despertou uma curiosidade, principalmente entre os flamenguistas, sobre a modalidade, atraindo novos fãs.

Em dois anos de projeto, o Flamengo eSports apresentou resultados impressionantes, como recordes de audiência, mais de 500.000 seguidores somados em suas redes sociais, patrocínios exclusivos com grandes marcas como Fusion, BS2, PicPay, Samsung, Redragon, DT3 e Buser, abrindo o mercado brasileiro a marcas não endêmicas, além do título, após 3 finais consecutivas, do CBLOL 2019, em uma partida histórica realizada diante de mais de 10.000 espectadores, na Jeunesse Arena, no Rio de Janeiro, contra a INTZ, tradicional time brasileiro, classificando o time para o Mundial da modalidade.

O sucesso do Flamengo despertou interesse de outros tradicionais clubes a investirem no mercado. Em outubro de 2019, o Corinthians, clube com segunda maior torcida do país, anunciou o lançamento do seu time de Free Fire, jogo desenvolvido pela Garena e muito popular no Brasil, devido à facilidade de funcionar em celulares básicos, principalmente com sistema Android, e assim se popularizando entre as classes C e D.

No cenário internacional, o time de futebol de maior relevância na indústria dos eSports é o clube francês Paris Saint Germain e seu time de Dota 2. Desde 2018 no comando do time, nascido da fusão com a LGD, equipe chinesa, o time francês já venceu por 2 vezes o The International, principal torneio da modalidade e acumula mais de U\$15 milhões em premiações. A entrada do PSG, como é popularmente conhecido o Paris Saint Germain, no cenário de eSports permitiu a disseminação da marca pela China, principal mercado de jogos eletrônicos do mundo, aumentando a popularidade e chamando atenção também para o time de futebol, modelo inverso ao adotado pelo Flamengo eSports que utilizou seu time de futebol para impulsionar o Flamengo eSports, o PSG.LGD utiliza da popularidade do esporte eletrônico, especialmente do Dota 2, na China para atrair um novo público para o time de futebol, principal esporte da agremiação. 
Como podemos observar, o esporte eletrônico é um mercado extremamente abrangente e ainda em fase de crescimento, oferecendo diversas possibilidades e oportunidades para o surgimento de novos negócios. Cases como o do Flamengo eSports, o do Corinthians e o do PSG.LGD ainda são raros no mercado. Como outros clubes brasileiros podem se aproveitar desse novo mercado, para atingir novos públicos, gerar novas receitas e fortalecer sua marca?

\subsection{Objetivo:}

O presente trabalho tem como objetivo fazer uma análise do cenário de esportes eletrônicos no Brasil, identificando estratégias para o desenvolvimento da modalidade em clubes tradicionais.

\subsection{Relevância do Estudo:}

O esporte eletrônico está em constante desenvolvimento. Atualmente o Brasil já está entre os principais mercados de games e eSports do mundo(2018 GLOBAL ESPORTS MARKET REPORT, NEWZOO), mas apesar disso existe um caminho muito grande a ser percorrido para atingir seu potencial. A relevância deste estudo se faz presente ao analisar como podemos atingir esse potencial, principalmente como uma organização tradicionalmente conhecida no futebol pode entrar na ind na indústria dos eSports, suas vantagens e desvantagens e como ela pode ser lucrativa do ponto de vista econômico.

\subsection{Delimitação do Estudo:}

Este trabalho se delimita única e exclusivamente a analisar estratégias para desenvolvimento do cenário de esportes eletrônicos brasileiro, especificamente de League of Legends, em clubes tradicionais do futebol brasileiro, os chamados 12 clubes grandes (Flamengo, Fluminense,Vasco da Gama, Botafogo, São Paulo, Palmeiras, Corinthians, Santos, Internacional, Grêmio, Cruzeiro e Atlético$M G)$. 


\section{Referencial Teórico}

\subsection{Esporte Eletrônico:}

Em sua definição, o esporte eletrônico é a "atividade de jogar jogos eletrônicos, contra outras pessoas na internet, frequentemente por dinheiro, podendo ser visto por outras pessoas em eventos organizados" (CAMBRIDGE DICTIONARY, eSports). O termo esporte eletrônico é relativamente moderno, que surgiu com a necessidade de diferenciar os esportes tradicionais das modalidades praticadas através de computadores e/ou videogames.

\subsection{Modelo VBR - Visão Baseada em Recursos}

Em seu artigo publicado em 1991 no Journal of Management, o autor Jay Barney descreve como as organizações podem obter uma vantagem competitiva sustentável a partir da análise dos recursos. Para Barney (1991), os recursos de uma firma consistem em todos os ativos tangíveis e intangíveis, humanos e não humanos possuídos e controlados por ela e que lhe permitem agregar valor a seus produtos e serviços (BARNEY, 1991). Ele cita três categorias principais de recursos: os físicos, os humanos e os organizacionais. Grant (1991) inclui ainda os recursos tecnológicos, financeiros e reputacionais (GRANT, 1991). O modelo é composto por 4 indicadores empíricos (valor, raridade, imitabilidade e organização) e permite, ao fim da análise, classificar se determinada organização possui uma vantagem competitiva sustentável frente a outras organizações. Nesse artigo, o autor afirma que "uma organização possui vantagem competitiva sobre as demais, se sua estratégia de criação de valor não está sendo simultaneamente implantada por outra organização" (BARNEY, 1991).

\subsubsection{Valor:}

Segundo o autor, para estabelecer uma vantagem competitiva sustentável, uma organização deve possuir recursos valiosos. Recursos valiosos são aqueles que permitem uma organização implementar estratégias mais eficientes e eficazes, permitindo-a explorar oportunidades e reduzir possíveis ameaças. 


\subsubsection{Raridade:}

Segundo o autor, um recurso raro é aquele não utilizado por concorrentes ou potenciais concorrentes. Quanto mais raro for um recurso obtido, mais chances tem a organização de possuir vantagem frente a outras.

\subsubsection{Imitabilidade:}

Semelhante ao conceito de recurso raro, para um recurso garantir à empresa vantagem competitiva ele deve ser difícil de imitar. Podem ser exemplos de recursos difíceis de imitar, produtos patenteados.

\subsubsection{Organização:}

A última análise a ser feita para certificar que certa organização possui vantagem competitiva frente às demais é se, com todos os recursos disponíveis, ela possui capacidade de utilizá-los da melhor forma de modo a garantir essa vantagem.

\subsection{Modelo das Cinco forças de Porter}

Em seu artigo na Harvard Business Review, publicado em 1979, o autor americano Michael E. Porter demonstrou pela primeira vez como as forças competitivas determinam a formulação da estratégia em uma organização. Confrontando o pensamento da época, Porter afirmou que "na luta pela parcela de mercado, a competição não é apenas manifestada por outros jogadores" (PORTER,1979). O autor definiu cinco principais forças, conforme o diagrama abaixo, onde " a força ou forças competitivas mais potentes determinam a rentabilidade de uma indústria, sendo, portanto, da maior importância na formulação de estratégia." (PORTER,1979). 


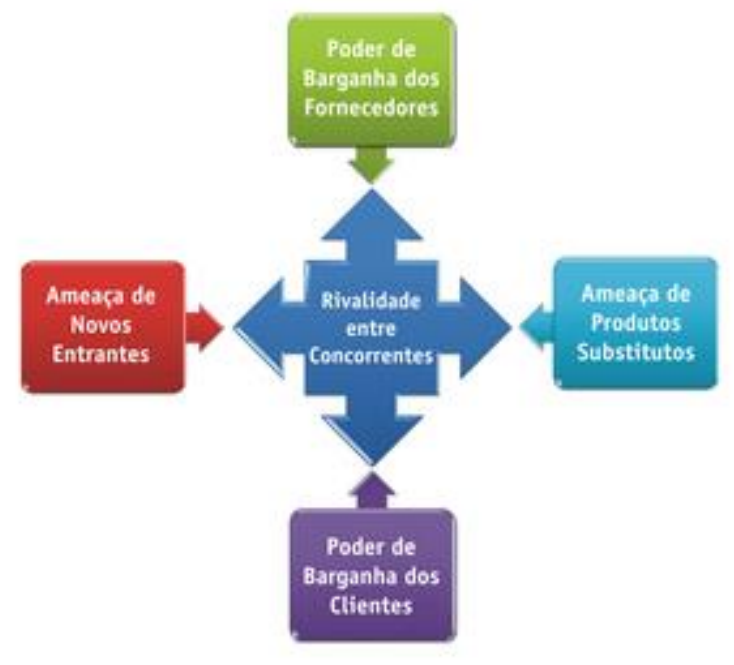

Figura 1: O Modelo das Cinco Forças de Porter (PORTER, M., 1979)

\subsubsection{Ameaça de novos entrantes:}

A primeira força analisada por Porter é a Ameaça de novos entrantes. "A seriedade da ameaça de novos concorrentes depende das barreiras existentes e da reação dos concorrentes já estabelecidos que os entrantes podem prever." (PORTER,1979), ou seja, segundo Porter, quanto maior for a barreira de entrada para novos entrantes, menos uma organização já estabelecida no setor será afetada. Entre as principais barreiras de entrada estão:

\subsubsection{Economia de escala}

O conceito de economia de escala dentro de estratégia não se define exclusivamente do ponto de vista econômico. Em estratégia, uma economia de escala, além de forçar um concorrente a entrar no mercado em larga escala ou aceitar desvantagem de custos (PORTER,1979), pode atuar como outras barreiras, entre elas distribuição, utilização da força de vendas ou financiamento (PORTER,1979) 


\subsubsection{Diferenciação de Produtos}

A principal barreira criada pela diferenciação de produtos está na identificação e lealdade do consumidor com uma marca já estabelecida. Esse fator obriga a nova entrante em um determinado mercado a conquistar o consumidor, algo que demanda altos investimentos principalmente em marketing.

\subsubsection{Necessidade de Capital}

Qualquer organização, no momento de seu lançamento, necessita de capital para funcionar. Porter afirma, porém que "a necessidade de investir um grande montante de recursos financeiros para competir cria uma barreira à entrada, particularmente se o capital é exigido para gastos não recuperáveis em publicidade antecipada ou em P\&D." Organizações em setores que necessitam de um alto investimento inicial tendem a criar maiores barreiras de entrada a novos entrantes.

\subsubsection{Acesso a canais de distribuição}

Para oferecer seus produtos e serviços ao público consumidor, uma organização deve obrigatoriamente ter acesso a canais de distribuição. Para certos produtos, os canais de distribuição podem ser pequenos e/ou controlados por outros players no mercado, dificultando a entrada de novos concorrentes.

\subsubsection{Poder de barganha dos fornecedores}

Fornecedores exercem poder de barganha frente a seu mercado consumidor em duas situações, principalmente: aumentando preços ou reduzindo a qualidade dos produtos/serviços vendidos. Um mercado onde fornecedores possuem alto poder de barganha se caracteriza pelas seguintes situações: mercado dominado por poucas companhias e/ou seu produto é exclusivo. 


\subsubsection{Ameaça de produtos substitutos}

A presença de produtos/serviços substitutos é talvez a mais conhecida das forças que influenciam na estratégia de uma organização. "Os substitutos - bens ou serviços que atendem à mesma necessidade básica do produto de um setor, de uma forma diferente - impõem um limite à lucratividade setorial" (MAGRETTA,2012). Apesar de ser a força mais conhecida, a ameaça de substitutos pode ser também a mais difícil de visualizar na formulação de uma estratégia. Segundo Joan Magretta, autora do livro "Entendendo Michael Porter", os substitutos não são necessariamente concorrentes e diretos, sendo comum o surgimento de fontes inesperadas. Preço, facilidade de uso, qualidade do produto são alguns dos fatores que determinam a escolha entre dois ou mais produtos substitutos.

\subsubsection{Poder de barganha dos clientes}

Clientes tendem a exercer pressão sobre as organizações principalmente quando há uma grande variedade de produtos substitutos no mercado ou realizam compras em grandes volumes. Produtos padronizados ou com baixa diferenciação são os mais comuns e passíveis de barganha por parte dos clientes, visto que podem comprar em diversos lugares, utilizando o fator preço como determinante na escolha.

\subsubsection{Rivalidade entre concorrentes}

A rivalidade entre concorrentes, diretos e indiretos, representa grande importância na análise da estratégia. Segundo Porter, "a rivalidade entre os concorrentes estabelecidos assume a forma familiar de manobras para conseguirem uma posição competitiva - utilizando táticas como concorrência de preço, lançamento de produtos, e agressivas campanhas publicitárias." (PORTER,1979), ou seja quanto maior a rivalidade entre os concorrentes do setor, maior será a barreira. 


\subsection{Análise SWOT}

A matriz SWOT (sigla para Strenghts, Weaknesses, Oportunities and Threats), ferramenta criada por professores da Universidade de Stanford e creditada a Albert Humphrey, visa identificar as Forças, Fraquezas, Oportunidades e Ameaças de uma determinada organização e/ou estratégia. A partir da identificação de todas as variáveis, relacionadas ao ambiente interno e externo das organizações, tem-se mais uma ferramenta para a formulação de estratégias e tomada de decisões.

\subsubsection{Forças}

A análise de forças de uma organização se baseia no que a empresa de destaca internamente. A análise de força procura identificar qualidades que separam determinada organização das demais atuantes no mercado. Uma empresa pode ter forças tangíveis, como ativos e capital disponível, ou intangíveis, como propriedade intelectual, know-how de mercado e patentes.

\subsubsection{Fraquezas}

Assim como a análise de forças, a análise de fraquezas também visa identificar aspectos internos de determinada organização. Nesse caso, a análise é tem como objetivo identificar onde uma organização falha, e onde concorrentes são melhores. As fraquezas também podem ser tangíveis, como limitação de recursos, ou intangíveis, como falta de conhecimento.

\subsubsection{Oportunidades}

A análise de oportunidades visa analisar o ambiente externo de uma organização. Nesse caso, o principal objetivo é identificar possíveis necessidades do mercado, de forma a atuar para suprir essas demandas. Podem ser consideradas oportunidades de mercados falta de oferta por certo produto, ou excesso de demanda pelo mercado consumidor. 


\subsubsection{Ameaças}

A análise de ameaças visa identificar o que pode afetar negativamente uma organização no futuro. Pode-se ter como exemplo novos competidores emergentes, possíveis regulamentações impostas pelo governo ou mudanças de comportamento do consumidor. 


\section{Metodologia de Pesquisa}

\subsection{Tipo de pesquisa}

Para ancorar a teoria proposta por este trabalho, será utilizada uma pesquisa descritiva qualitativa, com entrevistas com alguns dos principais agentes do meio dos esportes eletrônicos.

\subsection{Universo e amostra}

Para compor a pesquisa, foram selecionados agentes atuando no mercado de eSports. Foi utilizado um mesmo questionário para todos entrevistados, contendo perguntas sobre o cenário brasileiro, o desenvolvimento do mesmo e a participação de clubes tradicionais no meio, abordando suas vantagens e desvantagens para a indústria.

\subsection{Seleção da amostra}

A seleção da amostra foi feita de forma a abordar os principais players do mercado, possibilitando obter diferentes opiniões a respeito do assunto estudado. Os entrevistados são agentes altamente conceituados dentro da indústria dos esportes eletrônicos no país, critério principal para seleção dos mesmos. Para a pesquisa, a amostra selecionada foi:

- Thiago Milhazes - co-fundador da Cursor eSports, consultoria especializada em eSports e idealizadora do projeto do Flamengo eSports

- Gabriel Duarte - co fundador da Cursor eSports e Manager do Flamengo eSports sendo responsável por toda gestão estratégica do time, incluindo definição do modelo de negócios, estratégias de receita e gestão operacional do time.

- Felipe Borges - responsável pelas mídias sociais do Flamengo eSports, administrando e interagindo com mais de 500.000 seguidores. 


\subsection{Coleta de dados}

A coleta de dados foi realizada através de entrevistas individuais presenciais, e gravadas. Os entrevistados autorizaram o uso e divulgação de suas declarações para o presente trabalho.

\subsection{Tratamento de dados}

Após as entrevistas, as respostas foram transcritas para a realização das associações entre a opinião dos entrevistados, o referencial teórico e assim corroborar o objetivo do estudo. 


\section{Descrição dos Resultados}

\subsection{O preconceito com o esporte eletrônico}

Qualquer novo entrante no mercado enfrente uma resistência inicial por parte do mesmo. O caso dos esportes eletrônicos não é diferente. Uma das primeiras barreiras enfrentadas pelos esportes eletrônicos no Brasil é o preconceito com a modalidade. Desde o início houve o questionamento se esporte eletrônico seria ou não um esporte, como outro qualquer, e isso desencadeou uma onda de preconceito que ainda impede o desenvolvimento da modalidade no país. Segundo a pesquisa "O mundo invisível dos gamers", realizada em 2017 pelo Instituto Talk, $62 \%$ dos gamers costumam ouvir que esporte eletrônico é coisa de criança. Mais de $50 \%$ dos entrevistados também disseram ouvir que seria um vício e uma perda de tempo. O preconceito se escancara quando $33 \%$ dos gamers entrevistados dizem ouvir que games são para quem tem problemas para se socializar.

"O preconceito, na minha opinião, existe pela falta de conhecimento, principalmente por pessoas mais velhas. Mas eu tenho certeza que se você for numa sala de aula de $4^{\text {a }}$ série, $90 \%$ das pessoas, principalmente dos meninos, jogue algum jogo eletrônico. $A$ cultura está vindo com as novas gerações" - Thiago Milhazes

O preconceito impacta diretamente sobre o mercado. Marcas e organizações possuem bloqueios com o esporte eletrônico por medo da repercussão. Com clubes de futebol, o temor é ainda maior. Não é difícil, em fóruns voltados para a torcida do Flamengo ver publicações como a feita por Marion Kaplan, conselheira do Flamengo:

"Quem diria hein? O Flamengo divulgando um nerd da pior espécie, símbolo dos antiesportes, anti-atividade física...", Marion Kaplan, conselheira do Clube de Regatas do Flamengo em entrevista divulgada em reportagem do globoesporte.com em fevereiro de 2019.

Segundo Thiago Milhazes, um dos idealizadores do projeto do Flamengo eSports, o preconceito, e principalmente o desconhecimento foram a primeira barreira para iniciar a modalidade no clube. 


\subsection{Novo público consumidor}

Um dos principais fatores que atraem marcas, especialmente as não endêmicas, à indústria do esporte eletrônico é a possibilidade de se conectar a um novo público alvo. Isso se aplica também aos clubes de futebol. Por mais que não pareça e segundo dados do Ibope Repucom, o perfil de público e audiência de uma partida de futebol é majoritariamente de pessoas acima dos 50 anos $(+40 \%$ da audiência total). Isso demonstra que o futebol cada vez menos consegue atrair interesse da população mais jovem, especialmente até 24 anos, apenas $7,7 \%$ da audiência total. Por outro lado, o esporte eletrônico possui uma audiência muito mais nova, em que, segundos dados da Newzoo, 61\% da audiência é composta por Millenials, ou seja, na faixa dos 20 a 25 anos (NEWZOO,2018). Clubes que possuem projetos de esporte eletrônico podem, dessa forma, levar sua marca a um público muito jovem, aumentando sua base de fãs e consequentemente o valor de sua marca.

"Eu acho que [a entrada de times de futebol no mercado de esportes eletrônicos] têm muito a agregar para os dois lados. Você pega o case do Flamengo, que expandiu a marca dele para jovens que ele não atingia, mais pessoas estão curtindo o Flamengo, tendo inclusive relatos de pessoas que passaram a acompanhar o futebol do Flamengo por conta do League of Legends" - Thiago Milhazes

Além de ser um público jovem, o perfil de audiência do esporte eletrônico é composto de $78 \%$ de pessoas com hábitos de consumo de classes $A$ e $B$ (NEWZOO,2018). No futebol, as classes A e B correspondem apenas a aproximadamente $33 \%$ do público total, mostrando que além de dialogar com público de uma nova faixa etária, esse público também é altamente propenso a consumir produtos relacionados ao clube.

\subsection{Novos formatos de mídia}

O esporte eletrônico trouxe com ele uma nova forma de se assitir a uma transmissão. Enquanto no futebol as transmissões são vistas especialmente através da televisão, e de forma centralizada, no esporte eletrônico, cerca de $30 \%$ das pessoas não assistem qualquer tipo de TV. O formato de mídia mais conhecido no meio, é o streaming. Muito mais abrangente e gratuito, o streaming 
é a transmissão via internet. Atualmente as grandes plataformas de streaming pagam fortunas por canais exclusivos dos principais times e personalidades do meio. Para efeito de ordem de grandeza, Tyler Blevins, mais conhecido como Ninja, e maior streamer do mundo recebe somente da plataforma Mixer, da Microsoft, entre 6 a 8 milhões de dólares por ano em um contrato de 3 anos. Uma das principais plataformas de streaming, voltada para games e esporte eletrônico é a Twitch, com mais de 30 milhões de usuários mensais (Twitch Quantcast, 2017). Usualmente, as próprias plataformas, em modelo semelhante ao adotado pelo YouTube, pagam aos streamers um valor pela quantidade de usuários, além de permitir que esses streamers, em geral jogadores amadores e profissionais, insiram publicidade própria, como banners, em suas transmissões, além de propaganda via product placement e merchandising.

\subsection{Novos Patrocinadores}

Segundo dados da Newzoo, em 2019, o mercado de eSports irá movimentar, somente em patrocínios de empresas endêmicas e não endêmicas, cerca de 897,2 milhões de dólares. Esse valor corresponde a aproximadamente $82 \%$ de todo faturamento do mercado (NEWZOO ,2018). Novas fontes de receita talvez sejam o principal fator para a abertura de times de esporte eletrônico nos tradicionais clubes brasileiros. Aliando uma marca forte, a um novo público alvo e novos formatos de mídia, diversas marcas possuem interesse nesse mercado. Utilizando o case do Flamengo eSports, o time possui 10 patrocinadores, como PicPay, Banco BS2, Buser, Fusion Energy Drink, além de marcas endêmicas, com contratos exclusivos para o time de eSports, como Redragon, de periféricos, DT3, de cadeiras gamers e da Twitch, uma das principais plataformas de streaming do mundo.

O esporte eletrônico abriu oportunidade para diversas empresas consideradas endêmicas, ou seja, diretamente relacionadas ao meio eletrônico, de patrocinarem equipes e exporem sua marca para seu público alvo. É o caso de marcas de computadores, periféricos (acessórios para computadores), empresas de software, desenvolvedoras entre outras. Porém, diversas marcas não endêmicas, tem se associado ao esporte eletrônico, principalmente pela oportunidade de se aproximar de um público jovem e de classe social alta. 
Mundo a fora, temos diversos exemplos de marcas de luxo patrocinando equipes de esporte eletrônico.

Clubes tradicionais do futebol levam vantagem nesses casos, pois possuem uma marca com alta reputação no mercado e alta atratividade tanto de fãs quanto da imprensa especializada, oferecendo grande exposição para seus patrocinadores.

\subsection{Produtos Licenciados}

O mercado de produtos licenciados é o principal a ser explorado por grandes clubes de futebol que se iniciam no mercado de esporte eletrônico. Por já possuir uma grande base de fãs do futebol, o time de esporte eletrônico já se inicia com um potencial muito grande na venda de produtos licenciados. A diversidade de produtos que podem ser explorados em segmentos inéditos é enorme, principalmente acessórios para consoles e computadores, chamados de periféricos, além de peças de vestuário, como camisas, calças, casacos, tênis semelhantes aos utilizados pelos jogadores, assim como nos times de futebol. Além de produtos físicos, há ainda um grande mercado online, dentro dos próprios jogos, nas chamadas micro transações. Micro transações são as compras realizadas dentro dos jogos, como compra de artigos personalizados para os personagens (as skins). Um dos cases de maior sucesso é a parceria da NFL, a liga de futebol americano, com o jogo Fortnite, onde é possível que os usuários comprem e personalizem seu personagem com roupas licenciadas de todos os times da liga. Em um estudo realizado pela LendEDU, em 2018, com 1000 jogadores de Fortnite, 69\% disseram fazer compras dentro do jogo, nas chamadas micro transações, com um gasto médio de $\bigcup \$ 84,67$ cada um, mostrando a infinidade de produtos que podem ser licenciados, especialmente por marcas já consolidadas.

\subsection{Redes Sociais}

Por ser um mercado consumidor nativamente online, as redes sociais são fundamentais para o sucesso dos times. Além do alto número de seguidores, o público de esporte eletrônico é muito engajado nas redes sociais, capazes de converter diretamente ótimos resultados em campanhas de marketing 
realizadas. O Corinthians, com seu time de Free Fire, possui em apenas 2 meses de criação do time, mais de 200.000 seguidores em sua página no Instagram.

"As redes sociais do Flamengo eSports eram o principal meio de conexão do time com a torcida. Com um crescimento altamente orgânico, foi possível estabelecer um relacionamento muito próximo com os nossos seguidores. Esse alto número de interações, aliado com o alto número de seguidores, permitiu desenvolver campanhas com altas taxas de conversão para nossos patrocinadores" - Felipe Borges

Os jogadores profissionais também possuem um alto número de seguidores. $\mathrm{O}$ astro do Flamengo eSports, Felipe "brTT" Gonçalves, em comparação com o elenco profissional de futebol (dados de 2018), seria o terceiro com mais seguidores. Com seu estilo próprio, alinhado à marca Flamengo, altamente popular, o jogador engaja marcas a patrocinarem o clube.

\subsection{Vantagem competitiva}

Analisando a entrada de times de futebol no mercado de esporte eletrônico, podemos garantir, pelo modelo de Visão Baseada em Recursos (BARNEY,1991), que esses times possuem uma vantagem competitiva sustentável frente às demais organizações que desejam ingressar no mercado. Primeiramente, podemos afirmar que pelo tamanho e pelo valor do mercado, a criação de um time de eSports é um recurso valioso, devido ao potencial e a capacidade de gerar novas receitas. Quanto à raridade, a criação de uma nova equipe de esporte eletrônico não é algo exatamente raro, visto a facilidade para se criar uma. Nesse caso, a vantagem competitiva dos clubes de futebol é a de possuir uma marca forte e única no mercado, além do conhecimento no relacionamento com empresas, para captação de patrocínios, com a mídia, para difusão do time nos principais veículos de comunicação. Conhecidos nacionalmente, esses clubes tem enorme vantagem frente a novas equipes, despertando muito mais interesse de empresas, fãs e mídia. O recurso da imitabilidade, semelhante ao da raridade se aplica da mesma forma, em que uma marca forte nacional não pode ser copiada, possuindo vantagem sobre as demais. Por último, que certifica que os clubes de futebol possuem de fato uma vantagem competitiva sustentável, é a organização. Em sua grande maioria, os clubes citados possuem já uma estrutura funcional capaz de absorver a criação 
de um novo time. Além disso, são capazes de absorver o baixo custo de criação dessa organização. Apesar de, na maioria dos casos, não possuírem o knowhow para o desenvolvimento do time, existem cases no mercado, como o Flamengo eSports e o PSG.LGD que mostram que contratos de licenciamento e parcerias são eficazes e geram frutos à equipe.

\subsection{Forças de Porter}

Um mercado em expansão atrai interesse de muitos. Muitos aventureiros tendem a se lançar a qualquer custo, o chamado "FoMo", sigla para Fear of Missing Out, que significa o medo de estar de fora, e perder boas oportunidades (HERMAN, 2000). Porém apesar de parecer fácil e simples de se estabelecer nesse mercado, o esporte eletrônico possui algumas barreiras de entrada que podem dificultar novos entrantes. A primeira delas é a diferenciação de produtos. Atualmente diversas organizações já estão com suas marcas estabelecidas no cenário. Não é simples, apesar de ser possível, criar uma organização desconhecida do público e torná-la relevante no curto prazo de tempo. De fato muitas organizações surgem, esperando um rápido retorno econômico, que não se realiza, e elas logo são encerradas. Clubes de futebol são um ótimo exemplo no cenário de esporte eletrônico. Devido a sua tradição e conhecimento pelo grande público, eles automaticamente pulam essa primeira barreira, visto que atraem interesse de seus fãs apenas por existirem. Outra importante barreira de entrada é a necessidade de capital. Para a criação de uma organização de esporte eletrônico, que vise ser relevante no meio, é necessário um grande aporte de capital, criando mais uma barreira de entrada. Além do custo de computadores de última geração e específicos para games, são necessários jogadores, técnicos, fisioterapeutas, psicólogos, um local de treinamento, além de toda uma estrutura de backoffice para dar suporte ao time. A terceira barreira de entrada, que afeta de forma significativa novos entrantes é o acesso a canais de distribuição. O esporte eletrônico é bastante democrático para o espectador devido à natureza de transmissão ser feita majoritariamente por streaming. Qualquer organização pode criar uma conta, de forma gratuita, em uma das plataformas de streaming e transmitir suas partidas, sem necessitar de uma emissora que escolha seus jogos para transmitir. 
A segunda força descrita por Porter como forças atuantes que definem a estratégia e uma organização é o poder e barganha dos fornecedores. Essa força talvez seja a menos impactante, visto que uma organização de eSports não necessita de fornecedores constantes.

A próxima força é a ameaça de produtos substitutos. O esporte eletrônico funciona, principalmente para seu público consumidor, como uma forma de entretenimento. Dessa forma, a ameaça de produtos substitutos é enorme. Dentro da própria categoria de esporte eletrônico, uma modalidade, ou jogo, concorre diretamente com outro pela atenção do público, porém os grandes produtos substitutos estão fora do meio. Podemos citar como principal concorrente do esporte eletrônico, as plataformas de streaming, como o Netflix.

"Nós ganhamos através de tempo de tela do consumidor, tanto mobile quanto televisão, e temos uma grande variedade de competidores. Nós competimos (e perdemos) mais com "Fortnite", do que com a HBO" - Relatório de Resultados do Netflix em janeiro de 2019

Como consequência direta do grande número de concorrentes, a quarta força descrita por Porter também impacta diretamente no esporte eletrônico, o poder de barganha de clientes. Exatamente por ter diversas opções de modalidades e organizações para acompanhar, o consumidor/o fã exige um nível de qualidade de times e organizações muito grande, exigindo o máximo das mesmas sempre. Outro fator e diferentemente do futebol onde é raro ver alguém trocando de time frequentemente, o esporte eletrônico possui essa característica, especialmente por ser um mercado ainda muito novo, onde as grandes organizações estão ainda se consolidando, criando uma grande rivalidade entre todos os concorrentes, a quinta força descrita por Porter.

Uma equipe de futebol, com uma ideia estruturada e boa organização, é o modelo perfeito de entrada no mercado de eSports. Uma marca forte, uma grande base de fãs aliando a boa qualidade técnica de players e staff e com atenção da mídia conseguem canalizar as 5 forças de Porter a seu favor, criando estratégias competitivas que garantirão rapidamente o sucesso da organização, como aconteceu com o caso do Flamengo eSports. 


\subsection{Análise SWOT}

A análise SWOT da criação de um time de esporte eletrônico por um time tradicional de futebol pode ser um dos principais instrumentos para justificar o investimento. A matriz abaixo foi realizada considerando todos os 12 grandes clubes brasileiros e para uma organização de League of Legends, conforme descrito na delimitação do estudo.

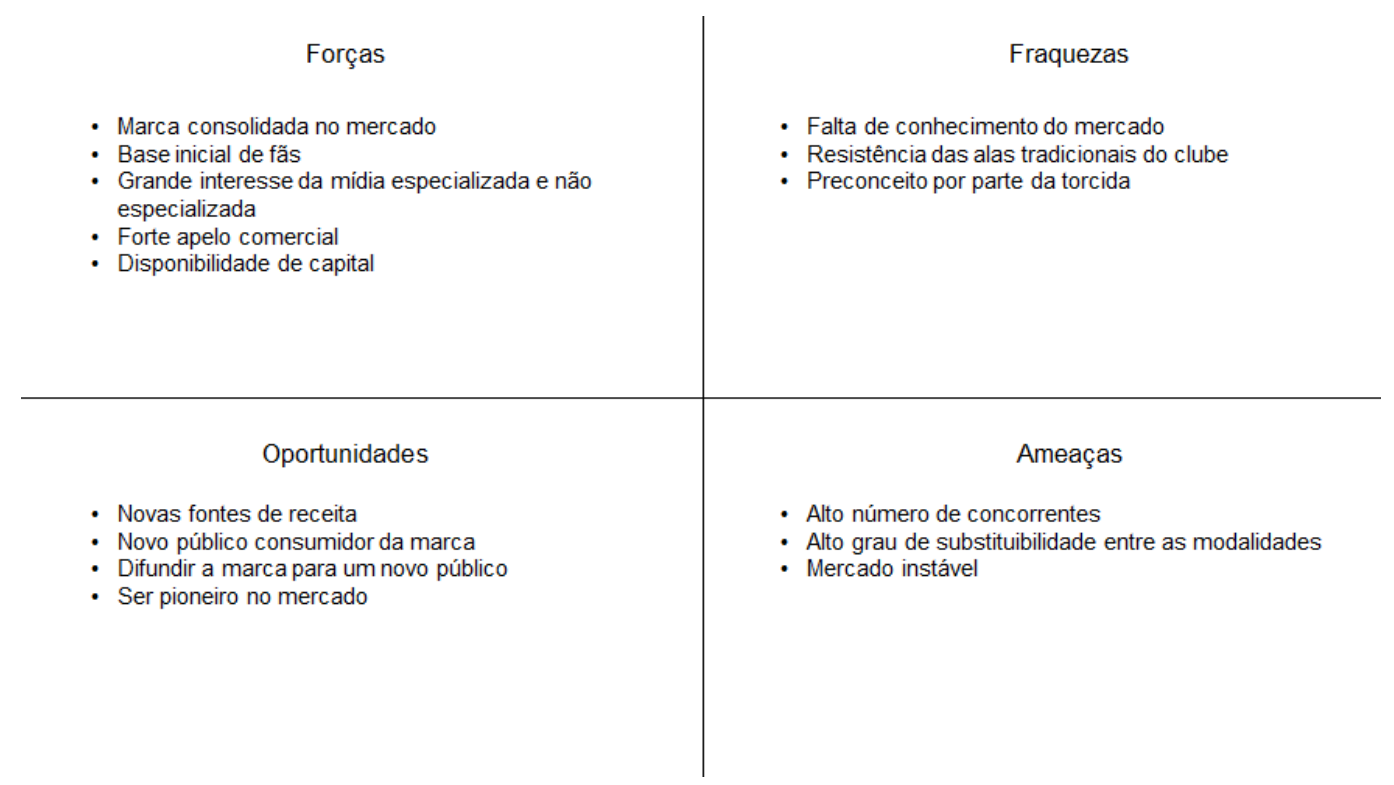

Figura 2 - Matriz SWOT - desenvolvido pelo autor

Ao se analisar a matriz SWOT do projeto de um time de League of Legends para um time tradicional de futebol, nota-se a quantidade de forças iniciais que ele possui. Entre as forças identificadas, três delas representam a principal barreira de entrada para se iniciar um time do zero: marca consolidada no mercado, e consequentemente com apelo comercial, base inicial de fãs e disponibilidade de capital.

"Diferente de outros projetos que iniciei no esporte eletrônico (ex: Submarino Stars, time de League of Legends patrocinado pela empresa Submarino), o case do Flamengo eSports teve início com metade do caminho andado, principalmente devido a força e a penetração da marca Flamengo no cenário brasileiro. O crescimento do time foi orgânico" - Gabriel Duarte

Uma das principais fraquezas é a falta de conhecimento dos clubes sobre o mercado, que como já houve exemplos, criam times para não perder o timing, mas não conseguem se organizar e acabam fracassando. Essa fraqueza pode 
ser facilmente contornada, com projetos de consultoria na área, como no Flamengo eSports, ou licenciamento da marca, como na equipe do Corinthians.

Analisando o cenário externo, as oportunidades são muito superiores em relação às ameaças. A principal ameaça é o risco, mesmo que pequeno, devido à consolidação da modalidade no cenário, do jogo ser uma moda e ser substituído como preferencia dos fãs. 


\section{Conclusão}

Ao decorrer deste estudo foi possível entender o tamanho e o potencial do mercado de esporte eletrônico no Brasil e no mundo. Enquanto alguns times de futebol já se aventuram nesse cenário, ainda temos espaço para a entrada de muitos outros, em diversas modalidades. Apesar de ainda engatinhar no cenário, o Brasil já possui um grande case no cenário, o Flamengo eSports, campeão do Campeonato Brasileiro de League of Legends e representante do país no mundial da modalidade em 2019, com todos seus recordes de audiência batidos, maior rede social entre os times brasileiros e grandes astros no time. $O$ Corinthians, com sua enorme torcida possui todo o potencial para se tornar mais um case de sucesso no cenário nacional, podendo chegar ao sucesso internacional, visto que o Brasil é uma das principais potências na modalidade de Free Fire. Uma comunidade extremamente fiel, que acompanha seus ídolos e torce por seus times, lotando arenas, consumindo produtos oficiais, assistindo transmissões nas plataformas de streaming e pressionando as grandes marcas a entrarem para esse mundo extremamente inclusivo. 


\section{Bibliografia}

BARNEY, Jay. Firm Resources and Sustained Competitive Advantage. Journal of Management, v. 17, n. 1, p. 99-120,1991

BENTO, Abner. Clubes de futebol e eSports: os times do Brasil que já investiram no competitivo dos games. E-Sportv, 16 abr. 2019. Disponível em $<$ https://sportv.globo.com/site/e-sportv/noticia/clubes-de-futebol-e-esports-ostimes-do-brasil-que-ja-investiram-no-competitivo-dos-games.ghtml> Acesso em: 19 out. 2019

BROWN, Mike. The Finances of Fortnite: How Much Are People Spending on This Game? Lendedu, 26 jun. 2018. Disponível em <https://lendedu.com/blog/finances-of-fortnite/> Acesso em 11 nov. 2019

COUTINHO, Beatriz. Free Fire: Todas as novidades do Corinthians nos esports. Versus, 11 out. 2019. Disponível em <https://vs.com.br/artigo/free-fire-todas-asnovidades-do-corinthians-nos-esports> Acesso em 18 out. 2019

COUTINHO, Beatriz. Forbes elege as empresas mais valiosas dos eSports; C9 e TSM lideram lista. Versus, 06 nov. 2019. Disponível em $<$ https://vs.com.br/artigo/forbes-elege-as-empresas-mais-valiosas-dos-esportsc9-e-tsm-lideram-lista> Acesso em 06 nov. 2019

GRANT, Robert M. The resource-based theory of competitive advantage: implications for strategy formulation. California Management Review, California, v. 33 , p. $114-135,1991$

HERMAN, Dan. Introducing short-term brands: A new branding tool for a new consumer reality. Journal of Brand Management, v.7, p 330-340, maio 2000.

IGLESIAS, Camila. Dois anos de Flamengo eSports: veja impacto do time no cenário de LoL. Techtudo, 05 out. 2019. Disponível em $<$ https://www.techtudo.com.br/noticias/2019/10/dois-anos-de-flamengo-esportsveja-impacto-do-time-no-cenario-de-lol-esports.ghtml> Acesso em: 18 out. 2019

LEE, David. Dota 2 May Become Major Driver of E-Sports in China. Pandaily, 30 jun. 2019. Disponível em <https://pandaily.com/dota-2-may-become-major-driverof-e-sports-in-china/> Acesso em 19 out. 2019

LIQUIPEDIA. PSG.LGD. Liquipedia, Disponível em <https://liquipedia.net/dota2/PSG.LGD> Acesso em: 18 out. 2019

MAGRETTA, Joan. Entendendo Michael Porter: o Guia Essencial da Competição e Estratégia. 1. ed. California: HSM, 2012.

NEWZOO. 2018 Global E-Sports Market Report. Newzoo. Disponível em $<$ https://newzoo.com/insights/trend-reports/newzoo-global-games-market-report2018-light-version/> Acesso em: 18 out. 2019 
PORTER, Michael E. How Competitive Forces Shape Strategy. Harvard

Business Review, mar. 1979

RAMOS, Erika Sales. Times de futebol que estão nos E-Sports: Conheça. Epic Play Brasil, jan. 2019. Disponível em <https://epicplay.com/times-de-futebolque-estao-no-e-sports-conheca/> Acesso em 19 out. 2019

TEIXEIRA, Chandy. Astro do LoL do Fla, brTT seria o terceiro mais popular do elenco de futebol na web. E-SporTV, 11 jan. 2018. Disponível em <https://sportv.globo.com/site/e-sportv/noticia/astro-do-lol-do-flamengo-brtt-seriao-terceiro-mais-popular-do-elenco-de-futebol.ghtml>. Acesso em 10 nov. 2019

VIANA, Bhernardo. How much money has Mixer paid Ninja to stream on its platform? Dot Esports, 02 ago. 2019. Disponível em $<$ https://dotesports.com/streaming/news/how-much-money-has-mixer-paid-ninjato-stream-on-its-platform> Acesso em 25 out. 2019

WEBB, Kevin. This 28-year-old makes $\$ 500,000$ every month playing 'Fortnite' here's how he does it. Business Insider, 13 ago. 2019. Disponível em $<$ https://www.businessinsider.com/ninja-tyler-blevins-twitch-subscribers-fortnitedrake-youtube-2018-3> Acesso em 19 out. 2019 


\section{Apêndices}

Roteiro Base de Entrevista com os Principais Participantes da Indústria de Esportes Eletrônicos.

1. O mercado de esporte eletrônico é relativamente novo, mas já atrai milhões de pessoas. Qual a sua relação com a indústria? O que te despertou interesse pela modalidade

2. Como você avalia o atual cenário nacional? Considerando as variáveis técnicas, infraestrutura, organização.

3. Em relação ao resto do mundo, como você enxerga o mercado nacional?

4. Você acha que existe preconceito contra o esporte eletrônico? Por quê?

5. Qual impacto do preconceito com a categoria? Você acredita que ele afeta o desenvolvimento da modalidade?

6. Como você enxerga a entrada, na visão do próprio clube, de times tradicionais do futebol no mercado de esporte eletrônico?

7. Por quais motivos você acredita que um time de futebol deve ter seu time de esporte eletrônico?

8. Quais benefícios podem ser obtidos?

9. Como você avalia o impacto sob o mercado da entrada dos times de futebol nos eSports?

10. Quais os principais fatores que levam um time de esporte eletrônico ser bem sucedido? 